\title{
Occupational Health and Safety Management: The Use of Personal Protective Equipment (Ppe) by Artisans in The Local Automotive Industry in Volta Region, Ghana

\author{
Augustine Abrampa Apreko ${ }^{\# 1}$, Lydia Sylvia Danku², Maxwell Selase Akple ${ }^{3}$ Adokou Faustin Apeletey $^{4}$ \\ ${ }^{\# 1 ’ 3}$ Department of Mechanical Engineering, Ho Polytechnic, Ghana \\ ${ }^{2}{ }^{4}$ Department of Secretaryship and Management Studies Ho Polytechnic, Ghana
}

\begin{abstract}
Personal Protective Equipment (PPE) plays a very important role in ensuring that artisans are healthy and safe in automotive workshops. Different studies have revealed that PPE is often not worn by workers in the informal sector in Ghana, and this undermines their general health and safety and leads to different types of injuries. This study focuses on the usage of PPE among local automotive artisans in Ghana. Questionnaires were administered to two hundred (200) artisans randomly selected which constituted the sample for the study.The results from the study revealed that majority of artisans understand the need for PPE usage for protection against accident, injury and illness and willing to practice it. However most artisans do not wear PPE because it is sometimes not available for use and in few cases where it is available the issue of comfort with respect to its usage needs to be addressed. Policies and regulations with respect to the use of PPE need to be developed and implemented in Ghana.
\end{abstract}

Keywords - Personal Protective Equipment, health and safety, automotive workshops, Local artisan.

\section{INTRODUCTION}

Workplace accidents and injuries are one of the most important preventable health problems throughout the world [1]. This is because such accidents could result in permanent body damage or death. According to Jovanovic et al. [2] each year occupational accidents result in staggering cost in terms of life, pain, suffering and loss of wages for injured worker. Therefore, it is very important for occupational safety and health to be taken seriously by workers. However, attentions for occupational health and safety are given to most workers in the formal sector whiles informal sector workers are neglected. Informal sector workers such as local automobile garages, carpenters, sprayers are key contributors to economic growth in developing countries. Similar study carried out in Tanzanians informal sector also shows that there is no guarantee of occupational health and safety for workers [3].

In Ghana, local garage workers are low-income workers, an occupation dominated by male workforce due to the amount of strength involved. Workers in the local garages are involved in various tasks such as vehicle servicing, spraying, auto electrician, welding. These tasks involve processes which exposed workers to physical and chemical agents that pose serious hazards to their health. According to a report by Harker et al. [4], workshop accidents result in considerable economic and human losses, low productivity, compensation and handicap. Despite the clear risks involved in informal work such as local garages, due to its unconventional nature and location, informal workers in most African countries are not protected by the institutions that officially govern occupational health and safety (OHS).
A study conducted by Lund and Marriot, [5] indicates that conventional OHS institutions have been designed to protect formal workers in formal work environments such as mines, factories, offices and shops, and so have no bearing on the working conditions of those who work in more unconventional settings. Part of the reason for this is that these institutions often take on narrowly focused, inflexible forms that are based on industrialised country models. Therefore, workshop safety and health practice standards for informal small sector industries is very important to prevent and or reduce occupational accidents and injuries. Workshop safety and health comprise of activities and practices which helps to reduce or prevent occupational accidents.

One key component of health and safety practices is the use of Personal Protective Equipment (PPE) [6]. PPE plays a vital role in ensuring overall health and safety to workers. According to Tanko and Anigbogu [7], PPE is defined in the UK Regulations 1992 as 'all equipment (including clothing affording protection against the weather) which is intended to be worn or held by a person at work and which protects him against one or more risks to his health or safety', e.g. safety helmets, gloves, eye protection, high visibility clothing, safety footwear and safety harnesses. PPE is equipment worn to minimize exposure to a variety of hazards; is also a method to protect a person from hot and cold temperatures. Where health risk cannot be avoided or processes cannot be improved, the use of appropriate PPE can also be effective measure to protect the health of workers.

Giving account of the development of personal protective equipment, McPherson and Shamis as cited by Tanko and Anigbogu [7] state that the initial focus was on protecting the worker and later, the focus shifted to worker comfort, functionality and performance issues, and finally to style issues. According to Occupational Health and Safety Council OSHC (2001) [8], PPE is an important means of preventing work injuries and should only be relied upon as a last line of defence in places where it is not practicable to control the hazards at source. OSHC (2001) states that the use of PPE generally implies working in a potentially hazardous work environment, and major means of injury prevention. Therefore, it is of prime importance to ensure that the equipment chosen is both reliable and effective, it is being properly used and maintained, and the user has undergone adequate training.

OSHC (2001) further outlined three key points on the proper use of PPE as proper selection, correct use, and correct maintenance. In proper selection, according to OSHC (2001), one must first understand the nature and degree of the potential hazards, and then select appropriate PPE that meets the relevant standards. Furthermore, some PPE (such as 
breathing apparatus) must properly fit the physique of the user before they can be effective. PPE must meet the demands of the work environment and should be as comfortable and easy to use as possible. Also, one must fully understand and abide by the correct usage methods of the PPE. Examples of incorrect use include different brands of filter being fitted to a respirator or the filters being cleaned with water.

OSHC (2001) maintains that PPE should be cleaned and dried after use, properly stored and regularly inspected. If you discover any damage to the PPE, you should immediately report this to your supervisor so that it can be replaced. This safety and health practice has been designed to prevent, control, reduce or eliminate occupational hazards and risks. It has been developed and applied continuously over the years to keep pace with technological and economic changes. Despite continuous improvements, occupational accidents and diseases are still too frequent in local automotive garages and their cost in terms of human suffering and economic burden continues to be significant.

A study conducted by Tanko and Anigbogu [7] revealed that though workers considered that protection against injuries is the most important characteristic of PPE, most of them do not wear the PPE provided on site. Such characteristics as appropriate size, lightweight and hygiene are also considered important by a considerable number of respondents in the study. Most of the workers according to Tanko and Anigbogu [7] feel that the PPE is uncomfortable, often oversized/undersized and not designed for hot weather and heavy.

About $12 \%$ of workers in a survey conducted by Taha [9] used personal protective measures all the time while $60 \%$ did not use any. The study also revealed that workers were exposed to a variety of occupational hazards with injuries and accidents forming the majority. Knowledge of workers in small industries about occupational hazards and their use of protective measures according to was inadequate [9]. Workers were exposed to a variety of occupational hazards mainly accidents and injuries. In developing countries such as Ghana, lack of knowledge on occupational health hazards and prevention such as PPE usage among local garage artisans is prevalent. In addition, there is little documentation or research concerning the use of PPE among local garage artisans in Ghana which undermines their general health and safety. Therefore the focus of this study is the use of PPE among local artisans in the automotive workshops in Volta Region in Ghana. Specifically focusing on the PPE availability, maintenance, user-friendliness and training.

\section{OCCUPATIONAL HEALTH AND SAFETY MANAGEMENT POLICY IN GHANA}

The issue of occupational health and safety in developing countries which Ghana is part is a serious problem. In Ghana, there is no comprehensive national OHS policy especially for the informal sector workers who also contribute to the growth of the economy. This challenge emanate from lack of OHS policy which should be part of national developmental agenda [10] Another challenge of poor OHS policy in Ghana is that policies do not effectively work. A study by Clark [11] shows that most of the legal provisions regarding OHS are very limited in scope and their focus is on the industries disregarding the informal sector. Some of the statutes which inform about implementation of occupational health and safety are the Factories, Offices and Shops Act 1970, Act 328 and the Mining Regulations 1970 LI 665 which drives OHS in manufacturing, shipping and mining sectors. Others include the Workmen's Compensation Law 1987, Environmental Protection Agency Act 490, 1994, and the Ghana Health Service and Teaching Hospitals Act 526, 1999 which do not even meet the international standard thus need modification [10].

\section{METHODOLOGY}

\section{Population and sampling}

The study was conducted in five municipalities' in the Volta Region of Ghana. In these municipalities, five key local garages made up of various specialist workshops were selected where most people within the municipalities serviced their vehicles. The specialist workshops had artisans such as auto mechanics, auto electricians, and welders. In addition, vehicle body sprayers and vulcanizers were also identified in the cities. In all, 30 specialist workshops including vehicle spraying and vulcanizers' workshops were involved in the study. It was estimated that the population of artisans were about 250 in all these local garages selected. Out of the 250 population, 200 artisans were randomly selected which constituted the sample for the study. All the selected artisans in the sample were interviewed by the authors and their trained assistants using a standardized questionnaire.

\section{Design of research instrument}

Questionnaire was the main data collection instrument used in this study. A set of items were developed for respondents to tick responses applicable to them. The questionnaire was in two parts. The first part focused on the biographical data of the respondents while the second part of the questionnaire covered the use of PPE. A five- point Likert scale $(1=$ strongly disagree $(\mathrm{SD}), 2=$ disagree $(\mathrm{D}), 3=$ neutral $(\mathrm{N}), 4=$ agree (A) and $5=$ strongly agree (SA)) was used to assign weight for the items on the questionnaire.

The researchers conducted pilot testing of the draft questionnaire with few potential respondents in an informal manner. The pilot test afforded the researchers the opportunity to correct the instrument for the main study and also enable the researchers to determine the reliability of the instrument.

\section{Data Collection Procedure}

Permission was sought from the various bodies that were involved in the study. On approval, the researchers selected artisans randomly from the various workshops that constituted the sample for the study. A convenient time was arranged with the workers for the administration of the questionnaire. All selected artisans in each workshop were put together on the 
International Journal of Engineering Trends and Technology (IJETT) - Volume 19 Number 4 - Jan 2015

appointed date and briefed on the objectives of the study and how to answer the questionnaire. The questionnaires were filled by the respondents and assistance given to respondents who had some difficulties by researchers and their trained assistants. The completed questionnaires were collected after the exercise.

\section{Data analysis}

The questionnaires were edited, coded and entered into Statistical Package for Social Scientist (SPSS) version 16 software. Tables comprising percentages and frequency were carried out using the SPSS to establish the relationship between variables.

\section{RESULTS AND DISCUSSION}

\section{Reliability Test}

Cronbach's alpha reliability test $(\alpha)$ was carried out to measure the correlation among the variables of the scale of item of the questionnaire. It is the most common measure of reliability (consistency) of a scale. The higher the Cronbach alpha value, the more consistent the research instrument is. In general, the accepted Cronbach alpha value is 0.7 and above, whiles a reliability coefficient of 0.6 is acceptable for exploratory research. In this study, the value of the Cronbach alpha test was 0.823 suggesting that all the items enumerated as variables for PPE are reliable and need to be retained as questions for the respondents.

\section{Biographical data}

Table 1 shows the biographical data of the respondents studied. The result indicates that all the respondents were males. This is because local automotive works is a masculine occupation in the study area. Majority of the respondents $(56 \%)$ were of the younger age bracket of 26-35 years. About $39 \%$ of the respondents had 6-10 working experiences which imply that they have enough experience to know about workshop hazards and safety management. In addition, most of the respondents $(57.5 \%)$ had up to basic education while $8.5 \%$ had no formal school education. About $86 \%$ of the respondents were masters at their workplaces and from different job specializations with most of them being auto mechanics.

\section{Personal Protective Equipment (PPE) usage}

In every workplace, workers are the first people exposed to potential occupational hazards. One key measure to reduce occupational accidents is the use of PPE which is unique for various occupations.

Table 1: Biographical variables of respondents

\begin{tabular}{lll} 
Variables & Frequency & $\%$ \\
\hline
\end{tabular}

\begin{tabular}{lcc}
\hline Gender & & \\
Male & 200 & 100.0 \\
\hline Age (years) & & \\
Under 25 & 27 & 13.5 \\
$26-35$ & 112 & 56.0 \\
$36-45$ & 51 & 25.5 \\
56 and above & 10 & 5.0 \\
\hline Work Experience (years) & & \\
Under 5 & 44 & 22.0 \\
6-10 & 78 & 39.0 \\
11-15 & 48 & 24.0 \\
16-20 & 13 & 6.5 \\
Above 20 & 17 & 8.5 \\
\hline Level of education & & \\
Informal & 17 & 8.5 \\
Basic & 115 & 57.5 \\
Secondary/Technical & 64 & 32.0 \\
Tertiary & 4 & 2.0 \\
\hline Job specialization & & \\
Auto Mechanics & 67 & 33.5 \\
Auto Electricians & 51 & 25.5 \\
Welders & 24 & 12 \\
Sprayers & 27 & 13.5 \\
Vulcanizers & 31 & 15.5 \\
\hline Positions at workshop & 172 & 86.0 \\
Master & 28 & 14.0 \\
Apprentice & & \\
\hline
\end{tabular}

In this study, most of the respondents agreed that PPE usage such as wearing of the prescribed attire for the workshop, use of strong workshop attire and shoes were enough to give them some amount of safety however, only $45.8 \%$ agreed (i.e. both SA and A) that they wear the prescribed attire in the workshop as shown in Table 2. Most respondents agreed that PPE are used to prevent specific body parts from being exposed to hazards. However, the result shows that some body parts were not protected by using PPEs. For instance, significant proportion of the respondent mentioned that they disagreed on the regular use of goggles to protect their eyes when working. They also disagreed on the wearing of respiratory devices when handling harmful materials. This could be due to the job specialization of the respondents. For example, an auto electrician and auto mechanics feel they do not need to wear goggles to protect their eyes. However, they are working in industrial area and sometimes in direct contact with petrol and diesel, exhaust gases, welding fumes, oils, solvents etc. Absorption of these harmful materials occur through direct inhalation, ingestion and direct skin contact which results in health problems such as lung diseases, dermatitis, eczema and respiratory and heart diseases( [12]-[13]).

Table 2: Personal protective equipment (PPE) usage by the respondents

Use of Personal protective equipment (PPE)

Responses (Percentages) 


\begin{tabular}{|c|c|c|c|c|c|c|}
\hline & & $\mathbf{S A}$ & $\mathbf{A}$ & $\mathbf{N}$ & DA & SDA \\
\hline 1 & I always wear the prescribed attire for the workshop & 15.3 & 30.5 & 20.3 & 22.0 & 11.9 \\
\hline 2 & $\begin{array}{l}\text { My workshop attire is strong enough to protect me at } \\
\text { work }\end{array}$ & 10.2 & 30.5 & 20.3 & 25.4 & 13.6 \\
\hline 3 & I always wear shoes at work to protect my feet & 23.7 & 27.1 & 11.9 & 23.7 & 13.6 \\
\hline 4 & I regularly protect my eyes with goggles when working & 11.9 & 16.9 & 23.7 & 27.1 & 20.3 \\
\hline 5 & I use gloves to protect my hands at work & 6.8 & 18.6 & 17.0 & 32.2 & 25.4 \\
\hline 6 & $\begin{array}{l}\text { I wear a respiratory device when handling harmful } \\
\text { materials }\end{array}$ & 11.9 & 10.2 & 23.7 & 27.1 & 27.1 \\
\hline 7 & I feel comfortable using personal protective equipment & 11.9 & 22.2 & 18.6 & 35.4 & 11.9 \\
\hline 8 & I regularly replace my worn-out PPE & 11.9 & 27.3 & 20.3 & 30.3 & 10.2 \\
\hline 9 & 1 am confident that I can use PPE properly & 15.3 & 37.3 & 25.4 & 15.3 & 6.8 \\
\hline 10 & I feel protected when not using the correct PPE & 17 & 22.0 & 27.1 & 23.7 & 10.2 \\
\hline
\end{tabular}

It was also surprising to note that most of the respondents disagree on the use of hand gloves to protect their hands. They were of the view that their hands need to be free for them to use to carry out workshop activities in exception of welders and vulcanizers. It was observed that their hands are body part which are easily bruised and with little wounds which they do not consider occupational accidents. This is consistent with Taha [9] who reported that hand injuries have now become a normal workshop accident which the respondents do not consider serious. Similarly cut-wounds on the hands and fingers and burns were the main accidents reported in small industries such as local garages. The report stated that the contributing factors to the high rates of accidents and injuries include low levels of education, lack of health education and the failure to use PPE.

The study further indicated that majority $(64.9 \%)$ of the respondents either disagreed or were neutral that they feel comfortable using PPE, $68 \%$ disagreed or were neutral on the regularly replacement of worn-out PPEs, however, most respondents were confident that they can use PPE properly. This shows that though respondents know the essence of PPE usage they feel uncomfortable using the PPEs. Most respondents $(61 \%)$ were neutral or disagreed in their response concerning whether they feel protected when not using the correct PPE. This is because they are used to not wearing

correct PPEs when working or inappropriate ones. This could also have a link with the unavailability of the appropriate PPEs in the study area. The study also shows that though respondents had knowledge of variety of preventive measures and PPEs, their use was unsatisfactory. The key reasons given by most respondents for not using PPE were non-availability of equipment, the PPEs were not designed for hot weather and that the equipment was too heavy causing inconvenience. This result is in line with other others studies ([7]-[9]).

\section{CONCLUSIONS}

The study revealed that the majority of workers understand the need for PPE and want to be protected against accident, injury and illness. However there is a need to address the issues of availability, comfort and education with respect to PPE usage to ensure that the equipment is properly used to protect the artisans. Proper maintenance and replacement of PPE would also go a long way in improving the practices of PPE use in automotive workshops in Ghana. Policies and regulations with respect to PPE need to be developed and implemented.

\section{ACKNOWLEDGEMENT}

The authors wish to express their profound gratitude to the various members of the Mechanical Engineering and Secretaryship and Management Studies departments of Ho Polytechnic for their diverse contribution to the success of this study. Further reseach assistants who helpled in data collection are all acknowledged.

\section{REFERENCES}

[1] V. S. Santana and D. Loomis (2004). Informal Jobs and Non-fatal Occupational Injuries Ann. occup. Hyg., 48 (2), 147-157.

[2] J. Jovanovic, M. Aranđelović and M. Jovanović (2004). Multidisciplinar Aspects of Occupational Accidents and injury. Work and Living Environmental Protection, 2(4), 325-333

[3] L.M.B., Rongo (2005). Are workers in small-scale industries in Dar es Salaam aware of occupational ergonomics principles? Afr News lett on Occup Health and Safety, 15, 14-16.

[4] C. Harker, A.B. Matheson, J.A.S. Ross and A. Seaton (1991). Accidents in the workplace. J Soc Occup Med, 41, 73-76. 
International Journal of Engineering Trends and Technology (IJETT) - Volume 19 Number 4 - Jan 2015

[5] F. Lund and A. Marriot (2005). Occupational health and safety for the poorest'. Final report of a consultancy for the Department of International Development. Durban: School of Development Studies, University of KwaZulu-NatalR. E. Sorace, V. S. Reinhardt, and S. A. Vaughn, "High-speed digital-to-RF converter," U.S. Patent 5668 842, Sept. 16, 1997.

[6] E. Pollit (2001). Managing Worker health \& Safety: An Auto Refinish shop Success Story. U.S EPA. Retrieved from www.epa.gov.

[7] B. L. Tanko, and N. A. Anigbogu (2012). The use of personal protective equipment (PPE) on construction sites in Nigeria In: Laryea, S., Agyepong, S.A., Leiringer, R. and Hughes, W. (Eds) Procs 4th West Africa Built Environment Research (WABER) Conference, 2426 July 2012, Abuja, Nigeria, 1341-1348
[8] OSHC Occupational Safety and Health Council (2001). Guidelines for the use of Personal Protective Equipment. Partnership in Safety.

[9] A. Z. Taha, (2000). Knowledge and practice of preventive measures in small industries in Al-Khobar. Saudi Medical Journal, 21 (8), 741.

[10] B. B. Puplampu and S.H. Quartey, (2012). Key Issues on Occupational Health and Safety Practices in Ghana: A Review. International Journal of Business and Social Science. . 3, 19.

[11] E. Clarke (2005). Do occupational health services really exist in Ghana? A special focus on the agricultural and informal sectors. Ghana Health Services ,Accra, Ghana.

[12] E.S. Hansen (1989). Mortality of auto mechanics: A ten-year follow-up. Scand J Work Environ Health, 15, 43-46

[13] A.,Saha, S. Kumar and D. Vasudevan (2008). Factors of occupational injury: a survey in a chemical company. Ind Health, 46, 152-7. 